\title{
Cause analysis of pipeline vibration in natural gas station
}

\author{
Jia $\mathrm{Wu}^{1,2}$, Shuai Kong ${ }^{1,2,{ }^{*}}$, Li Xia ${ }^{1,2}$ and Ping Tang ${ }^{1,2}$ \\ ${ }^{1}$ Zhejiang Academy of Special Equipment Science, Hangzhou, China \\ ${ }^{2}$ Key Laboratory of Special Equipment Safety Testing Technology of Zhejiang Province, Hangzhou, China
}

\begin{abstract}
Natural gas station is an important part of the whole natural gas pipeline transmission system, in which the pipeline vibration is a hidden danger that cannot be ignored for the safe operation of the station. In view of the severe vibration of the pipeline in a natural gas station of an enterprise, the vibration acceleration sensors are used to test the vibration of each measuring point under different working conditions, and then the three-dimensional finite element model of the pipeline is established by using numerical simulation software to study its structural characteristics and gas column characteristics. Through the analysis of field test results and simulation results, it is found that there are two main vibration frequencies in the pipeline: 116.75 Hz and $123.0 \mathrm{~Hz}$. The former is caused by the resonance between the gas column frequency and the natural frequency in pipe B; The latter is due to the impact of the gas column force in pipe A on pipe B.
\end{abstract}

\section{Introduction}

In the process of natural gas transmission, the abnormal vibration of the pipeline in the natural gas station will loosen and rupture the connection parts of the pipeline accessories, ranging from leakage to explosion, resulting in serious accidents. Therefore, it is necessary to analyze the vibration of the pipeline system, find out the causes of the vibration, and take effective measures to reduce the vibration.

The research on pipeline vibration has been favored by technicians of scientific research institutes and major engineering companies. Its main research directions focus on two aspects: the analysis of dynamic characteristics of pipeline structure and the analysis of aerodynamic characteristics in pipe.

In the analysis of dynamic characteristics and dynamic response of pipeline structure, the characteristics of natural frequency, vibration amplitude and stress of pipeline structure have always been the focus of theoretical research by many scholars. Housner [1] replaced the pipe model with the beam model, and assumed to ignore the structural damping, gravity, fluid pressure and external tensile pressure, calculated the vibration equation of long straight pipe with equal wall thickness. However, this method is not applicable to calculate the natural frequency of complex pipeline system under space conditions. In this case, the methods often used to calculate the natural frequency are finite element method and transfer matrix method. Jia et al. [2] established the finite element model of variable crosssection liquid filled pipeline, analyzed the vibration frequency of the pipeline system, and judged whether the resonance frequency may occur through the analysis results. Sutar et al. [3] simulated the model of fluid transmission pipeline through finite element analysis, and studied the effects of end conditions on the natural frequency, static and fluid flow conditions of empty pipe. Irie et al. [4] referred to the Timshenko beam model and deduced the vibration and stability of the flow transmission pipeline by using transfer matrix method. Lesmez et al. [5] made a further innovation on the vibration transfer matrix method of spatial pipeline system, and gave priority to the variable separation method when deriving the characteristic matrix of pipeline. Li et al. [6] studied the vibration analysis of liquid pipeline system, and extended the frequency domain analysis of fluid-structure interaction from single pipe to multi-pipe system by using the transfer matrix method. Liu et al. [7] derived the transfer formulas of deflection, angle, bending and shear between two adjacent spans of multi span pipeline by using the matrix transfer method, and gave the natural frequency equation and vibration mode function between adjacent spans of multi span pipeline. $\mathrm{Li}$ et al. [8-10] established a 14 equation model to describe the fluid-structure coupling behavior of the pipeline, and then analyzed the effects of support, structural performance and fluid parameters on the dynamic response and natural frequency of the pipeline by using the transfer matrix method. Based on the transfer matrix method, Batura et al. [11] proposed an effective method for calculating the static and dynamic stress and residual strength of complex space pipeline considering the internal vibration of fluid and Poisson coupling. Guidara et al. [12] used the transfer matrix method and Laplace transform to calculate the natural frequencies of the system under different boundary conditions considering fluid-structure coupling.

In studying the gas dynamic characteristics of pipeline, the main means of scientific researchers is to calculate the natural frequency of gas column by analyzing the gas column parameters (such as gas pressure, gas density and

\footnotetext{
* Corresponding author: wujiachn@126.com
} 
gas flow velocity), and establish and improve the mathematical model. Kinsler et al. [13] deduced the plane wave theory through the study of gas in pipe and a series of specific assumptions. Mohri and Hayama [14] appropriately modified the plane wave theory by assuming that the damping is directly proportional to the square of the gas velocity, and expanded the application range of the plane wave theory to apply it to the resonance region. MacLaren et al. [15] considered the influencing factors of the resonance region, such as the average velocity and the heat exchange of the gas, and obtained the unsteady equations. With the help of computer technology, the equations can solve the results of gas pulsation with high precision. The experimental verification is relatively consistent, and the mathematical model of gas pulsation is further improved. Kriesels et al. [16] studied the flow characteristics in a pipe system with two opposite closed side branches of equal length. Tonon et al. [17] discussed the flow-induced pulsation in a resonant pipe network with closed branches, and proposed a single-mode model for predicting self-sustained oscillation. Okuyama et al. [18] conducted several air flow experiments at room temperature and pressure to study the effects of geometric parameters and flow parameters on general acoustic resonance. Xiao et al. [19] experimentally studied the effects of branch length and edge geometry on the acoustic resonance characteristics of closed side branches. With the in-depth research on the basic theory and experimental methods of pipeline vibration by scientific researchers and technicians, more and more pipeline vibration problems have been effectively solved.

In this paper, aiming at the problem of severe pipeline vibration in a natural gas station of an enterprise, the vibration acceleration sensor is used to test the variable condition vibration of each measuring point of the pipeline, and then combined with numerical simulation, the vibration data are analyzed to find out the causes of pipeline vibration.

\section{Model and Method}

\subsection{Distribution of measuring points}

The tested pipeline in the natural gas station are shown in Figure 1. Natural gas is transmitted from pipe A to pipe B through tee, and then transmitted to the downstream through buried pipeline. The nominal diameter of pipe A is $800 \mathrm{~mm}$ and the wall thickness is $16 \mathrm{~mm}$. The nominal diameter of pipe $\mathrm{B}$ is $1000 \mathrm{~mm}$ and the wall thickness is $18.4 \mathrm{~mm}$.

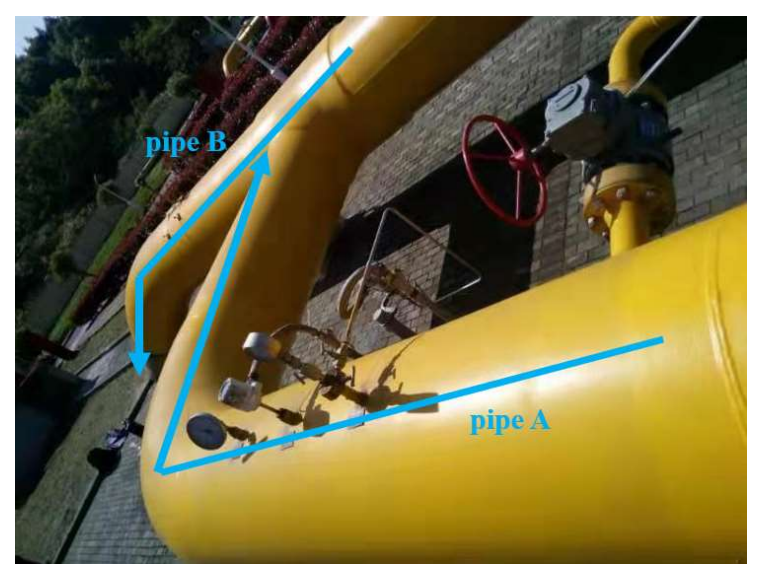

Figure 1. Tested pipeline in natural gas station

The vibration acceleration sensors are used to test the vibration of the pipeline. The measuring points are distributed on pipe A and pipe $\mathrm{B}$. The measuring points on pipe A are measuring point 4 (MP4) and measuring point 5 (MP5) respectively, and the measuring points on pipe $\mathrm{B}$ are measuring point 1 (MP1), measuring point 2 (MP2) and measuring point 3 (MP3) respectively, as shown in Figure 2.

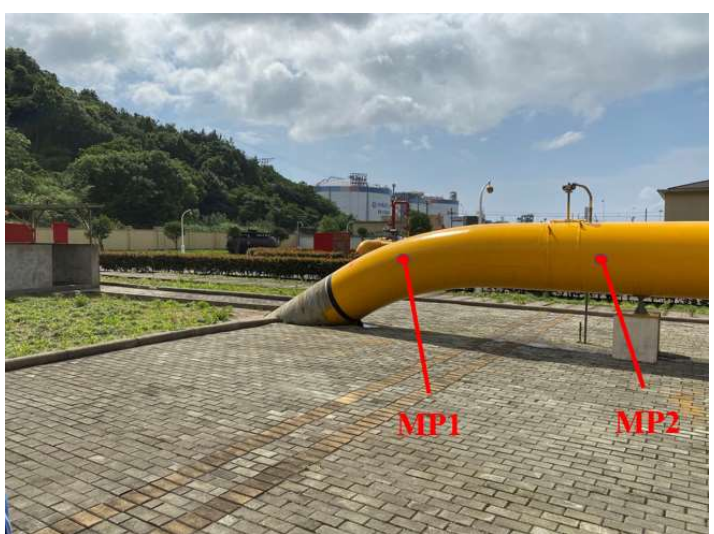

(a) MP1 and MP2

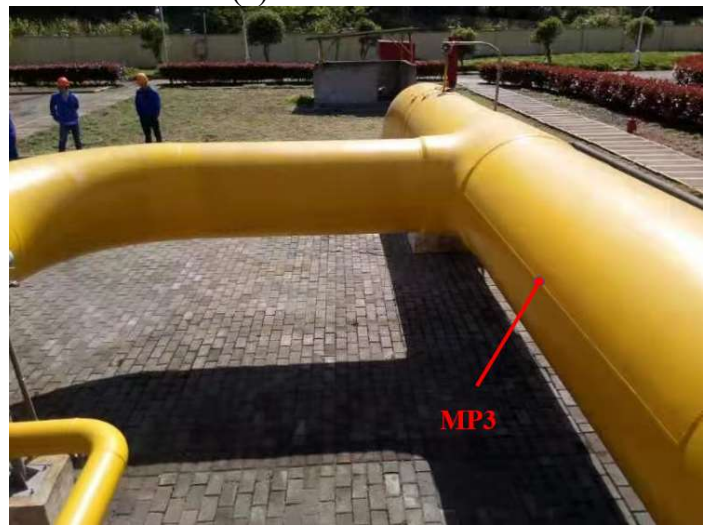

(b) MP3 


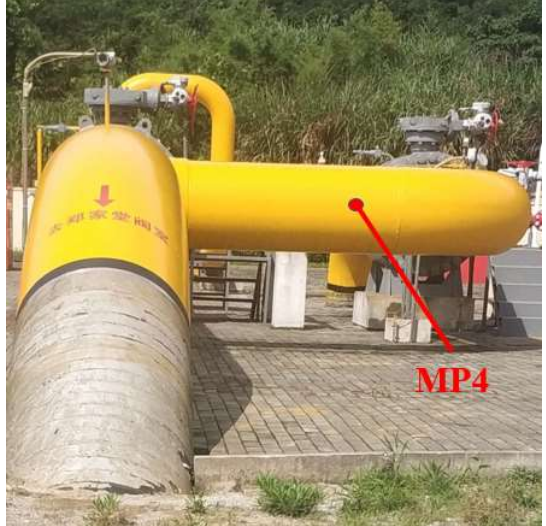

(c) MP4

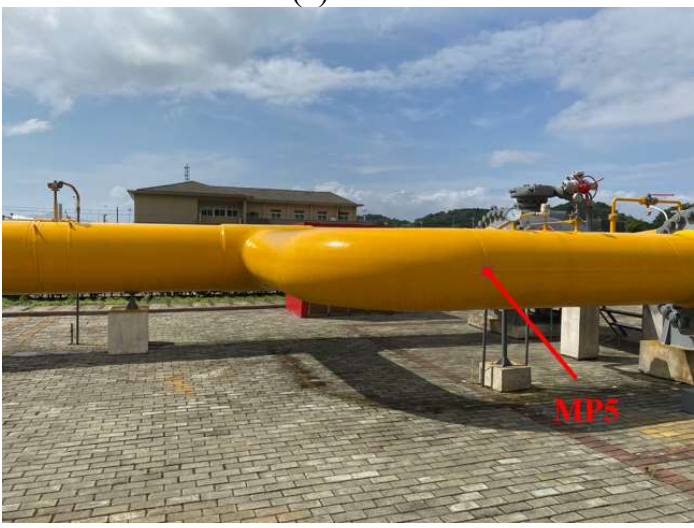

(d) MP5

Figure 2. Distribution of measuring points

\subsection{Simulation model}

The three-dimensional model of the pipeline is established by using ANSYS software, as shown in Figure 3. The unit type adopts three-dimensional sound unit, the medium in the pipe is natural gas, the density is 44.12 $\mathrm{kg} / \mathrm{m}^{3}$, and the sound velocity is $430.1 \mathrm{~m} / \mathrm{s}$. At the closed valve, the boundary condition is set as acoustic closure. At the pipe inlet, the boundary condition is set as acoustic opening.

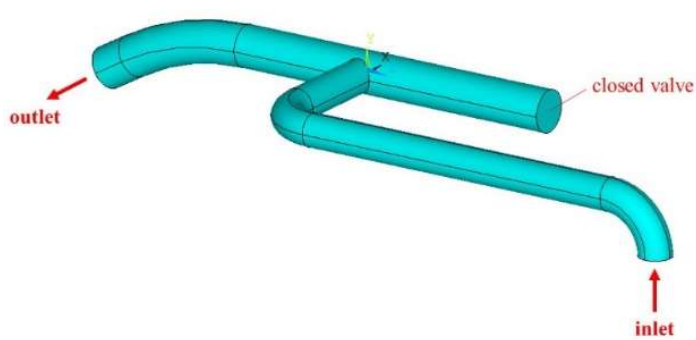

Figure 3. Three-dimensional model of pipeline

\subsection{Simulation method}

It is assumed that the gas in the pipeline is compressible and there is no average flow. According to the continuity equation and momentum equation, the acoustic wave equation [20] can be obtained:

$$
\begin{aligned}
& \nabla \cdot\left(\frac{1}{\rho_{0}} \nabla \mathrm{p}\right)-\frac{1}{\rho_{0} c^{2}} \frac{\partial^{2} p}{\partial t^{2}}+\nabla \cdot\left[\frac{4 \mu}{3 \rho_{0}} \nabla\left(\frac{1}{\rho_{0} c^{2}} \frac{\partial p}{\partial t}\right)\right] \\
& =-\frac{\partial}{\partial t}\left(\frac{Q}{\rho_{0}}\right)+\nabla \cdot\left[\frac{4 \mu}{3 \rho_{0}} \nabla\left(\frac{Q}{\rho_{0}}\right)\right]
\end{aligned}
$$

where, $\rho_{0}$ is the average fluid density, $p$ is the acoustic pressure, $c$ is the sound velocity in the fluid medium, $t$ is the time, $\mu$ is the dynamic viscosity and $Q$ is the mass source.

The finite element expression of acoustic wave equation is obtained by using Galerkin method and finite element approximate shape function:

$$
\begin{aligned}
& \iiint_{\Omega_{F}} \frac{1}{\rho_{0} c^{2}}\{N\}\{N\}^{T} d V\left\{\ddot{p}_{e}\right\}+\iiint_{\Omega_{F}} \frac{4 \mu}{3 \rho_{0}^{2} c^{2}}[\nabla N]^{T}[\nabla N] d V\left\{\dot{p}_{e}\right\} \\
& +\iint_{\Omega_{F}} \frac{1}{\rho_{0}}[\nabla N]^{T}[\nabla N] d V\left\{p_{e}\right\}+\oiiint \oiiint_{\Gamma_{F}}\{N\}\{n\}^{T}\left\{N^{\prime}\right\}^{T} d s\left\{\ddot{u}_{e, F}\right\} \\
& =\iiint_{\Omega_{F}} \frac{1}{\rho_{0}}\{N\}\{N\}^{T} d V\{\dot{q}\}+\iiint_{\Omega_{F}} \frac{4 \mu}{3 \rho_{0}^{2}}[\nabla N]^{T}[\nabla N] d V\{q\}
\end{aligned}
$$

Where, $\{N\}$ is the element shape function of pressure, $d V$ is the volume differential of sound domain $\Omega_{F},\left\{P_{e}\right\}$ is the node pressure vector, and $d s$ is the surface differential of sound field boundary $\Gamma_{F},\{n\}$ is the normal vector outside the fluid boundary, $\left\{N^{\prime}\right\}$ is the element shape function of displacement, $\left\{u_{e}\right\}$ is the node displacement vector, $\{q\}$ is the node mass source vector, and $\{\dot{q}\}$ is the first derivative of the node mass source vector.

The above equation can be expressed by matrix to obtain the following discrete wave equation:

$$
\left[M_{F}\right]\left\{\ddot{p}_{e}\right\}+\left[C_{F}\right]\left\{\dot{p}_{e}\right\}+\left[K_{F}\right]\left\{p_{e}\right\}+\bar{\rho}_{0}[R]^{T}\left\{\ddot{u}_{e, F}\right\}=\left\{f_{F}\right\}
$$

were,

$\left[M_{F}\right]=\bar{\rho}_{0} \iiint_{\Omega_{F}} \frac{1}{\rho_{0} c^{2}}\{N\}\{N\}^{T} d V \quad$, is the mass matrix of acoustic fluid;

$\left[C_{F}\right]=\bar{\rho}_{0} \iiint_{\Omega_{F}} \frac{4 \mu}{3 \rho_{0}{ }^{2} c^{2}}[\nabla N]^{T}[\nabla N] d V, \quad$ is the damping matrix of acoustic fluid;

$\left[K_{F}\right]=\bar{\rho}_{0} \iiint_{\Omega_{F}} \frac{1}{\rho_{0}}[\nabla N]^{T}[\nabla N] d V$, is the stiffness matrix of acoustic fluid; $[R]^{T}=\oiint_{\Gamma_{F}}\{N\}\{n\}^{T}\left\{N^{\prime}\right\}^{T} d s$, is the boundary matrix of acoustic fluid;

$\left\{f_{F}\right\}=\bar{\rho}_{0} \iiint_{\Omega_{F}} \frac{1}{\rho_{0}}\{N\}\{N\}^{T} d V\{\phi\}+\bar{\rho}_{0} \iiint_{\Omega_{F}} \frac{4 \mu}{3 \rho_{0}^{2}}[\nabla N]^{T}[\nabla N] d V\{q\}$, is the load vector of acoustic fluid; $\bar{\rho}_{0}$ is the mass density constant of acoustic fluid.

\section{Measurement results}

\subsection{Natural frequency measurement}

The natural frequency measurement is carried out by pulse excitation method. By analyzing the frequency spectrum of pulse response, the natural frequency of each pipe section can be obtained. 
Figure 4 shows the vibration spectra of MP1 in the vertical direction without excitation and excitation, and Figure 5 shows the vibration spectra of MP1 in the horizontal direction without excitation and excitation. As can be seen from Figure 4, when not excited, the frequency of MP1 is mainly $116.0 \mathrm{~Hz}$, while when excited, the frequency still exists, but the amplitude increases sharply. This shows that the natural frequency of MP1 in the vertical direction is $116.0 \mathrm{~Hz}$. Similarly, it can be seen from Figure 5 that the natural frequency of MP1 in the horizontal direction is also $116.0 \mathrm{~Hz}$.

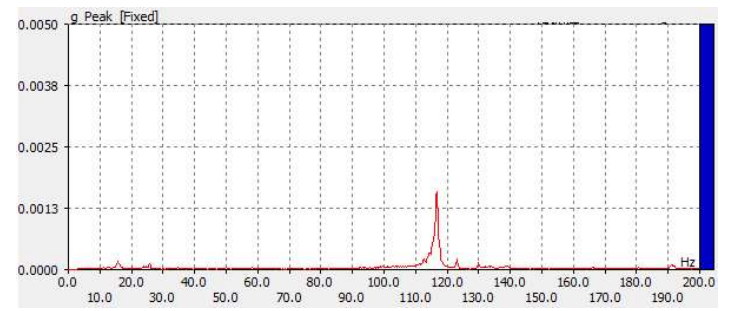

(a) without excitation

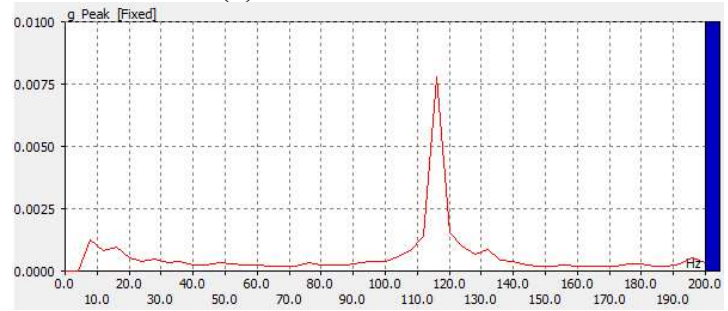

(b) under excitation

Figure 4. Vibration spectra of MP1 in vertical direction without excitation and excitation

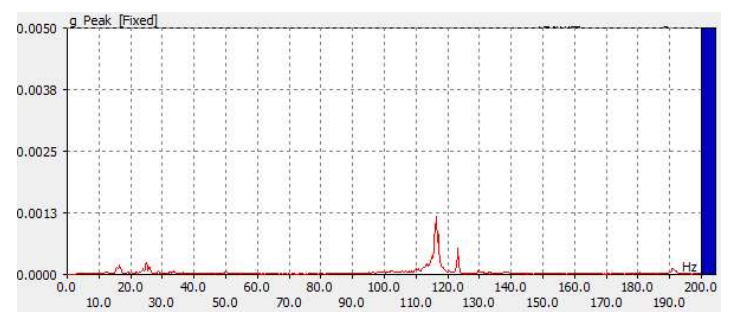

(a) without excitation

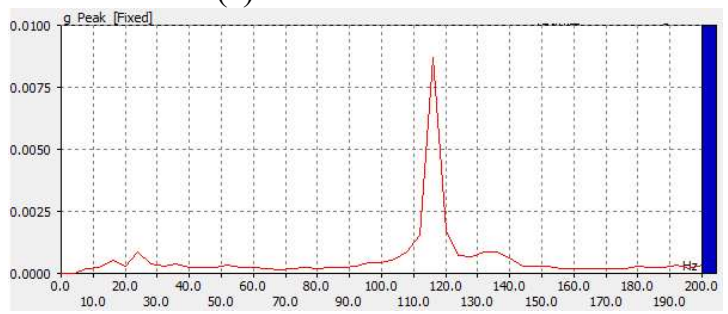

(b) under excitation

Figure 5. Vibration spectra of MP1 in horizontal direction without excitation and excitation

The discussion of other measuring points is similar to the above. In order to reduce redundancy, the vibration spectrum figures of other measuring points are no longer placed in this paper. Instead, Table 1 lists the natural frequencies of all measuring points in both vertical and horizontal directions. It should be noted that there is a vertical support near MP2 (see Figure 2(a)), so the natural frequency measured by pulse excitation method is not obvious.

Table 1. Natural frequencies of all measuring points in vertical and horizontal directions

\begin{tabular}{cccccc}
\hline & MP1 & MP2 & MP3 & MP4 & MP5 \\
\hline Vertical & 116.0 & & 198.0 & 284.0 & 272.0 \\
direction & $\mathrm{Hz}$ & - & $\mathrm{Hz}$ & $\mathrm{Hz}$ & $\mathrm{Hz}$ \\
Horizontal & 116.0 & 200.0 & 198.0 & 284.0 & 288.0 \\
direction & $\mathrm{Hz}$ & $\mathrm{Hz}$ & $\mathrm{Hz}$ & $\mathrm{Hz}$ & $\mathrm{Hz}$ \\
\hline
\end{tabular}

\subsection{Comparison between normal and vibration} conditions

Figure 6 and 7 show the time domain waveforms and spectra of MP4 under normal and vibration conditions. It can be seen from the figures that under normal condition, the vibration is very small, while under vibration condition, the vibration increases sharply, and the vibration frequencies are $116.75 \mathrm{~Hz}$ and $123.0 \mathrm{~Hz}$.

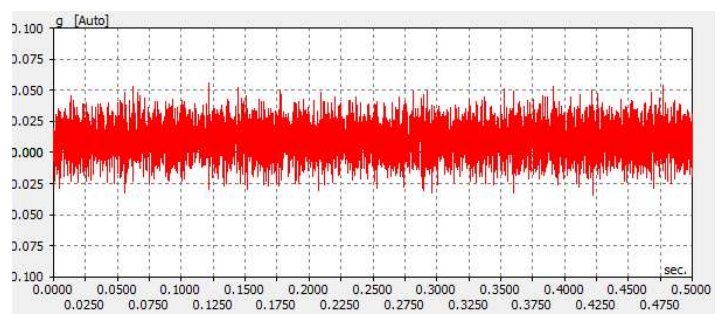

(a) time domain waveform

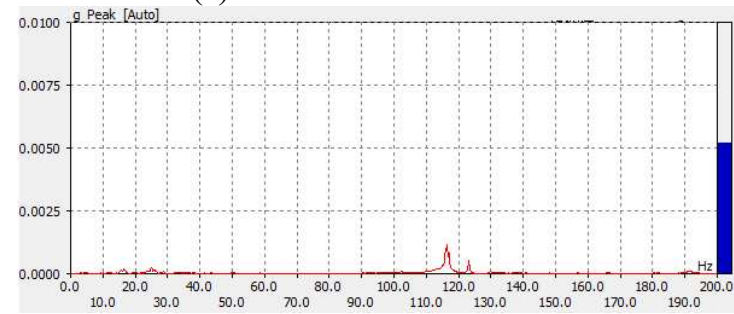

(b) spectrum

Figure 6. Time domain waveform and spectrum of MP4 under normal condition

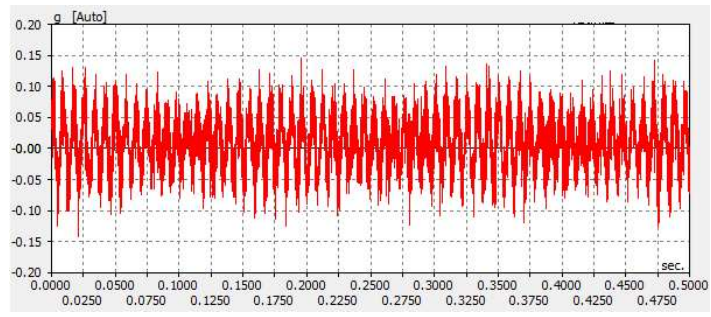

(a) time domain waveform

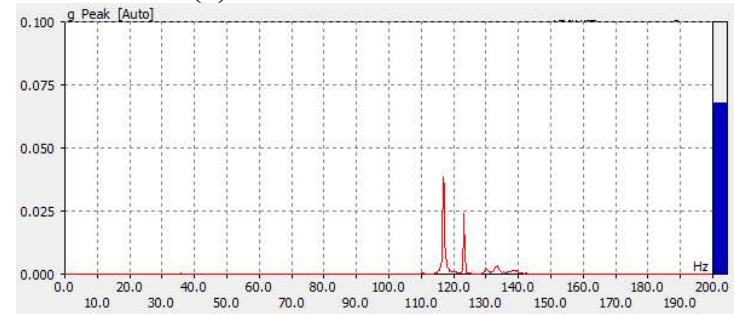

(b) spectrum

Figure 7. Time domain waveform and spectrum of MP4 under vibration condition 
The discussion of other measuring points is similar to the above. In order to avoid redundancy, the time domain waveforms and spectra of other measuring points under two working conditions are not placed in this paper. Instead, Table 2 lists the main vibration frequencies and peak-peak values of all measuring points under normal and vibration conditions. It can be seen from the table that the main vibration frequencies of each measuring point are about $116.75 \mathrm{~Hz}$ and $123.0 \mathrm{~Hz}$ under both normal and vibration conditions. Under the vibration condition, the vibration of each measuring point increases sharply (more than ten times larger than that under the normal condition). The maximum vibration is located at MP1, because the natural frequency of MP1 is $116.0 \mathrm{~Hz}$, which may form resonance and cause severe vibration. In addition, the vibration component of $123.0 \mathrm{~Hz}$ is also large. In order to understand this phenomenon, it is necessary to conduct numerical simulation analysis of the pipeline.

Table 2. Main vibration frequencies and peak-peak values of all measuring points under two working conditions

\begin{tabular}{|c|c|c|c|c|}
\hline $\begin{array}{l}\text { Working } \\
\text { condition }\end{array}$ & $\begin{array}{l}\text { Measuring } \\
\text { point }\end{array}$ & Direction & $\begin{array}{c}\text { Main } \\
\text { vibration } \\
\text { frequencies }\end{array}$ & $\begin{array}{l}\text { Peak- } \\
\text { peak } \\
\text { value }\end{array}$ \\
\hline \multirow{10}{*}{$\begin{array}{c}\text { normal } \\
\text { condition }\end{array}$} & \multirow{2}{*}{ MP1 } & vertical & $\begin{array}{r}116.75 \mathrm{~Hz} \\
123.0 \mathrm{~Hz}\end{array}$ & $0.025 \mathrm{~g}$ \\
\hline & & horizontal & $\begin{array}{l}116.5 \mathrm{~Hz} \\
123.75 \mathrm{~Hz}\end{array}$ & $0.025 \mathrm{~g}$ \\
\hline & \multirow{2}{*}{ MP2 } & vertical & $\begin{array}{c}116.5 \mathrm{~Hz} \\
123.0 \mathrm{~Hz}\end{array}$ & $0.021 \mathrm{~g}$ \\
\hline & & horizontal & $\begin{array}{l}116.5 \mathrm{~Hz} \\
123.25 \mathrm{~Hz}\end{array}$ & $0.025 \mathrm{~g}$ \\
\hline & \multirow{2}{*}{ MP3 } & vertical & $\begin{array}{c}116.5 \mathrm{~Hz} \\
123.5 \mathrm{~Hz}\end{array}$ & $0.025 \mathrm{~g}$ \\
\hline & & horizontal & $\begin{array}{l}116.5 \mathrm{~Hz} \\
123.25 \mathrm{~Hz}\end{array}$ & $0.025 \mathrm{~g}$ \\
\hline & \multirow{2}{*}{ MP4 } & vertical & $\begin{array}{r}116.75 \mathrm{~Hz} \\
123.0 \mathrm{~Hz}\end{array}$ & $0.031 \mathrm{~g}$ \\
\hline & & horizontal & $\begin{array}{r}116.75 \mathrm{~Hz} \\
123.0 \mathrm{~Hz}\end{array}$ & $0.031 \mathrm{~g}$ \\
\hline & \multirow{2}{*}{ MP5 } & vertical & $\begin{array}{c}116.5 \mathrm{~Hz} \\
123.5 \mathrm{~Hz}\end{array}$ & $0.031 \mathrm{~g}$ \\
\hline & & horizontal & $\begin{array}{l}116.5 \mathrm{~Hz} \\
123.25 \mathrm{~Hz}\end{array}$ & $0.030 \mathrm{~g}$ \\
\hline \multirow{10}{*}{$\begin{array}{l}\text { vibration } \\
\text { condition }\end{array}$} & \multirow{2}{*}{ MP1 } & vertical & $\begin{array}{l}116.75 \mathrm{~Hz} \\
123.25 \mathrm{~Hz}\end{array}$ & $0.50 \mathrm{~g}$ \\
\hline & & horizontal & $\begin{array}{l}117.0 \mathrm{~Hz} \\
123.25 \mathrm{~Hz}\end{array}$ & $0.57 \mathrm{~g}$ \\
\hline & \multirow{2}{*}{ MP2 } & vertical & $\begin{array}{c}116.75 \mathrm{~Hz} \\
123.25 \mathrm{~Hz}\end{array}$ & $0.27 \mathrm{~g}$ \\
\hline & & horizontal & $\begin{array}{l}116.75 \mathrm{~Hz} \\
123.25 \mathrm{~Hz}\end{array}$ & $0.38 \mathrm{~g}$ \\
\hline & \multirow{2}{*}{ MP3 } & vertical & $\begin{array}{r}116.75 \mathrm{~Hz} \\
123.0 \mathrm{~Hz}\end{array}$ & $0.35 \mathrm{~g}$ \\
\hline & & horizontal & $\begin{array}{c}116.75 \mathrm{~Hz} \\
123.25 \mathrm{~Hz}\end{array}$ & $0.48 \mathrm{~g}$ \\
\hline & \multirow{2}{*}{ MP4 } & vertical & $\begin{array}{r}116.75 \mathrm{~Hz} \\
123.0 \mathrm{~Hz}\end{array}$ & $0.37 \mathrm{~g}$ \\
\hline & & horizontal & $\begin{array}{r}116.75 \mathrm{~Hz} \\
123.0 \mathrm{~Hz}\end{array}$ & $0.17 \mathrm{~g}$ \\
\hline & \multirow{2}{*}{ MP5 } & vertical & $\begin{array}{r}116.75 \mathrm{~Hz} \\
123.0 \mathrm{~Hz}\end{array}$ & $0.32 \mathrm{~g}$ \\
\hline & & horizontal & $\begin{array}{r}116.75 \mathrm{~Hz} \\
123.0 \mathrm{~Hz}\end{array}$ & $0.36 \mathrm{~g}$ \\
\hline
\end{tabular}

\section{Simulation results}

Aiming at the problems of unknown vibration frequency and unknown vibration cause in the measurement results, the finite element model of the pipeline is established by using ANSYS software, the variation laws of different order vibration modes are obtained, the gas column frequency of the pipeline is calculated and compared with the excitation frequency, so as to effectively determine the cause of pipeline vibration.

Figure 8 shows the vibration modes of pipe A and pipe $\mathrm{B}$ obtained by simulation calculation. As can be seen from the figures, pipe $\mathrm{B}$ has both vertical and horizontal vibration, while pipe $\mathrm{A}$ is mainly horizontal vibration.

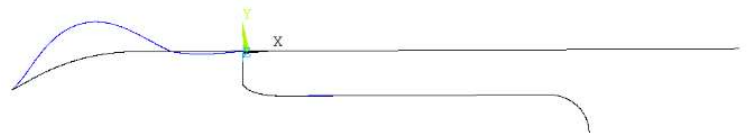

(a) vertical vibration

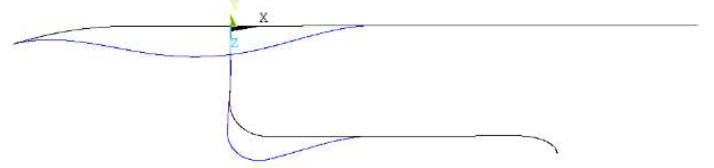

(b) horizontal vibration

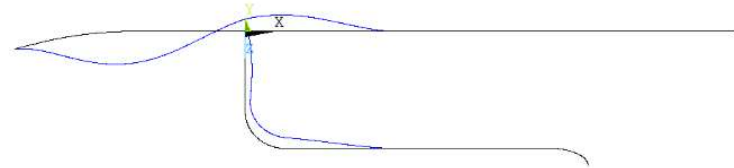

(c) horizontal vibration

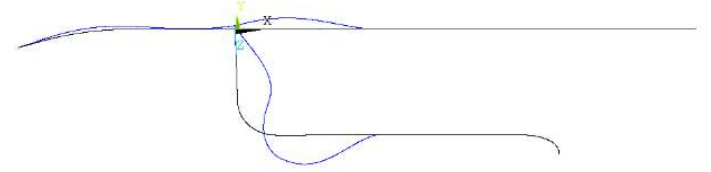

(d) horizontal vibration

Figure 8. Vibration modes of pipe A and pipe B

The contour plots of gas column are obtained through simulation calculation, as shown in Figure 9. In Figure 9(a), the gas column is mainly located on pipe B. It is generated due to the acoustic closure of pipe B. Its frequency is estimated to be $117.8 \mathrm{~Hz}$ by simulation, which is close to the vibration frequency of $116.75 \mathrm{~Hz}$. In Figure 9(b), the gas column is mainly located on pipe A, which will impact pipe $\mathrm{B}$. The simulation estimates that the gas column frequency is $128.0 \mathrm{~Hz}$, which is close to 123.0 Hz obtained from field measurement.

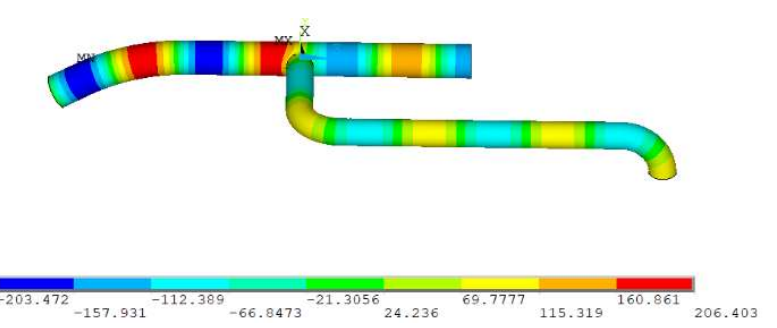

(a) $117.8 \mathrm{~Hz}$ 


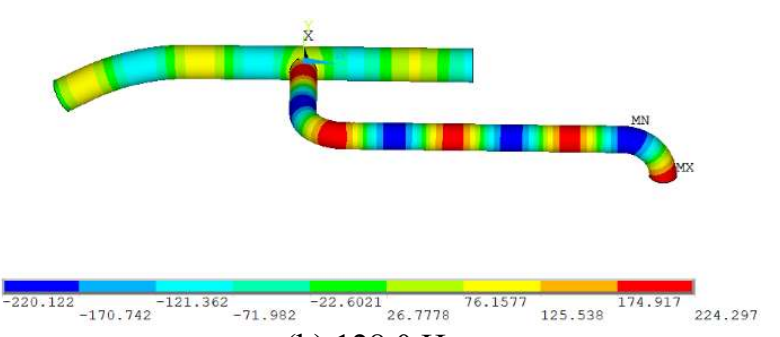

(b) $128.0 \mathrm{~Hz}$

Figure 9. Contour plots of gas column at different frequencies

\section{Conclusion}

The field vibration measurement and simulation calculation show that there is a gas column excitation source in the pipeline. The gas column propagates outward along the pipeline and will arouse strong vibration when encountering the unreasonable pipeline. There are two main vibration frequencies: $116.75 \mathrm{~Hz}$ and $123.0 \mathrm{~Hz}$. The former is caused by the resonance between the gas column frequency and the natural frequency in pipe $\mathrm{B}$; The latter is due to the impact of the gas column force in pipe $A$ on pipe $B$. In order to reduce the vibration of the pipeline, it is recommended to increase the stiffness of the buried pipe section in pipe B and change the length of the straight pipe section between the tee and the elbow in pipe $\mathrm{A}$.

\section{Acknowledgments}

This work was financially supported by the science and technology project of Zhejiang Provincial Administration for Market Regulation (NO. 20210116).

\section{References}

1. Housner, G. W. (1952). Bending vibrations of a pipe line containing flowing fluid. Journal of Applied Mechanics, 19(2), 205-208.

2. Jia, Y., Madeira, R. E., \& Just-Agosto, F. (2005). Finite element formulation and vibration frequency analysis of a fluid filled pipe. In ASME International Mechanical Engineering Congress and Exposition (Vol. 42282, pp. 127-132).

3. Sutar, S., Madabhushi, R., \& Poosa, R. B. (2016). Finite element analysis of piping vibration with guided supports. Int. J. Mech. Eng. Autom, 3(3), 96106.

4. Irie, T., Yamada, G., \& Takahashi, I. (1980). Vibration and stability of a non-uniform Timoshenko beam subjected to a follower force. Journal of Sound and Vibration, 70(4), 503-512.

5. Lesmez, M. W., Wiggert, D. C., \& Hatfield, F. J. (1990). Modal analysis of vibrations in liquid-filled piping systems. Journal of Fluids Engineering, 112(3), 311-318.

6. Li, Q. S., Yang, K., Zhang, L., \& Zhang, N. (2002). Frequency domain analysis of fluid-structure interaction in liquid-filled pipe systems by transfer matrix method. International Journal of Mechanical Sciences, 44(10), 2067-2087.

7. Liu, J., He, X., Liu, Q., Naibin, J., \& Chen, H. (2014). Vibration-modal analysis model for multi-span pipeline with different support conditions. Computer Modelling \& New Technologies, 18(5), 14-18.

8. Li, S. J., Liu, G. M., \& Kong, W. T. (2014). Vibration analysis of pipes conveying fluid by transfer matrix method. Nuclear Engineering and Design, 266, 78-88

9. Li, S., Karney, B. W., \& Liu, G. (2014). Application of transfer matrix method to dynamic analysis of pipes with FSI. In Pressure Vessels and Piping Conference (Vol. 46025, p. V005T11A005). American Society of Mechanical Engineers.

10. Wu, X. D., Liu, G. M., \& Chen, H. (2012). The analysis of natural characteristics of pipeline structure systems based on frequency-domain transfer matrix method. Advanced Materials Research, 383-390, 4541-4545.

11. Batura, A., Novikov, A., Pashchenko, A., \& Dubyk, Y. (2019). An application of the transfer matrix approach for a dynamic analysis of complex spatial pipelines. Nuclear Engineering and Design, 349, 174182.

12. Guidara, M. A., Taieb, L. H., \& Taïeb, E. H. (2015). Determination of Natural Frequencies in Piping Systems Using Transfer Matrix Method. In Design and Modeling of Mechanical Systems-II (pp. 765774). Springer, Cham.

13. Kinsler, L. E., Frey, A. R., Coppens, A. B., \& Sanders, J. V. (2000). Fundamentals of acoustics. John wiley \& sons.

14. Mohri, Y., \& Hayama, S. (1987). Resonant Amplitudes of Pressure Pulsation in Pipelines: Calculations by the Equivalent Linearization Method of $|\mathrm{q}| \mathrm{q}$ ): Vibration, Control Engineering, Engineering for Industry. JSME International Journal, 30(262), 602-607.

15. MacLaren, J. F. T., Tramschek, A. B., Sanjines, A., \& Pastrana, O. F. (1975). A comparison of numerical solutions of the unsteady flow equations applied to reciprocating compressor systems. Journal of mechanical engineering science, 17(5), 271-279.

16. Kriesels, P. C., Peters, M. C. A. M., Hirschberg, A., Wijnands, A. P. J., Iafrati, A., Riccardi, G., ... \& Bruggeman, J. C. (1995). High amplitude vortexinduced pulsations in a gas transport system. Journal of Sound and Vibration, 184(2), 343-368.

17. Tonon, D., Hirschberg, A., Golliard, J., \& Ziada, S. (2011). Aeroacoustics of pipe systems with closed branches. International Journal of Aeroacoustics, 10(2-3), 201-275.

18. Okuyama, K., Tamura, A., Takahashi, S., Ohtsuka, M., \& Tsubaki, M. (2012). Flow-induced acoustic resonance at the mouth of one or two side branches. Nuclear engineering and design, 249, 154-158.

19. Xiao, Y., Zhao, W., Gu, H., \& Gao, X. (2018). Effects of branch length and chamfer on flow-induced 
acoustic resonance in closed side branches. Annals of Nuclear Energy, 121, 186-193.

20. ANSYS Inc. (2013). "ANSYS $®$ Mechanical APDL, Release 15.0, Help System, Acoustics," ANSYS, Canonsburg, PA. 